\title{
Article \\ Experimental Verification and Analytical Approach for Electromagnetic Characteristics of a High-Speed Permanent Magnet Motor with Two Different Rotors and Winding Patterns
}

\author{
Jong-Hyeon Woo $\mathbb{B}$, Tae-Kyoung Bang $\mathbb{D}$, Jeong-In Lee, Hoon-Ki Lee and Jang-Young Choi * \\ Department of Electrical Engineering, Chungnam National University, Daejeon 34134, Korea; \\ dnwhd0@cnu.ac.kr (J.-H.W.); bangtk77@cnu.ac.kr (T.-K.B.); lji477@cnu.ac.kr (J.-I.L.); lhk1109@cnu.ac.kr (H.-K.L.) \\ * Correspondence: choi_jy@cnu.ac.kr; Tel.: +82-42-821-7601
}

\section{check for}

updates

Citation: Woo, J.-H.; Bang, T.-K.; Lee, J.-I.; Lee, H.-K.; Choi, J.-Y.

Experimental Verification and

Analytical Approach for

Electromagnetic Characteristics of a

High-Speed Permanent Magnet

Motor with Two Different Rotors and

Winding Patterns. Appl. Sci. 2021, 11,

9060. https://doi.org/10.3390/

app11199060

Academic Editor: Jeihoon Baek

Received: 29 July 2021

Accepted: 23 September 2021

Published: 28 September 2021

Publisher's Note: MDPI stays neutral with regard to jurisdictional claims in published maps and institutional affiliations.

Copyright: (c) 2021 by the authors. Licensee MDPI, Basel, Switzerland. This article is an open access article distributed under the terms and conditions of the Creative Commons Attribution (CC BY) license (https:// creativecommons.org/licenses/by/ $4.0 /)$.

\begin{abstract}
In general, high-speed machines should be designed with high efficiency electromagnetic and mechanical characteristics. It is important to analyze the electromagnetic loss for a design with high efficiency. In this study, the effects of the magneto-motive force and time harmonics of the stator current according to the winding distribution of a high-speed permanent magnet motor on the electromagnetic characteristics were comparatively analyzed using analytical methods and FEM. In addition, the final model was proposed by analyzing the relationship between the magnet usage according to the rotor shape and the electromagnetic and mechanical properties according to the winding patterns. Finally, the optimal model was manufactured and the validity was experimentally verified.
\end{abstract}

Keywords: high speed motor; winding pattern; current harmonic; eddy current loss

\section{Introduction}

Recently, high-speed machines have been studied extensively with great interest due to the advantages of higher power density, increased reliability, and miniaturization than conventional medium speed or low speed electric machines [1]. Among them, in the case of high-speed permanent magnet (PM) motors, eddy current causes demagnetization owing to heat, which can have a serious effect on efficiency of the high-speed machine. Therefore, eddy current loss in the high-speed rotation region is one of the important research areas of research [2]. The primary causes of this eddy current loss are space harmonics of magneto-motive force (MMF) due to winding distributions and time harmonics of stator current due to motor driver carrier harmonics [3,4]. The harmonics of the carrier harmonics have a great influence on the electromagnetic losses when compared with the sinusoidal currents. Therefore, when analyzing high-speed PM motors, electromagnetic loss analysis considering carrier harmonics is essential. In addition, MMF due to winding distribution is an important factor in reducing back EMF harmonics, torque ripple, eddy current loss, saturation, noise and vibration [5,6]. In this paper, the effects of the MMF and time harmonics of the stator current according to the winding distribution of a high-speed PM motor on the electromagnetic characteristics were comparatively analyzed using analytical methods and FEM.

For most high speed motors, a two-pole cylindrical magnet rotor, which is advantageous in terms of control perspective, is frequently used [7]. Therefore, in this paper, a combination of two poles and six slots was selected and the electromagnetic characteristics according to the concentrated and the distributed winding patterns were comparatively analyzed. In addition, the final model was proposed by analyzing the relationship between the magnet usage according to the rotor shape and the electromagnetic and mechanical properties according to the winding patterns. Finally, the optimal model was manufactured and the validity was experimentally verified. Figure 1a shows the 3D structure of two 
different winding patterns, Figure $1 \mathrm{~b}$ shows the 3D rotor shape structure along the hollow shaft, and Figure 1c shows the manufacturing model to which the hollow shaft and the concentrated winding pattern are applied.

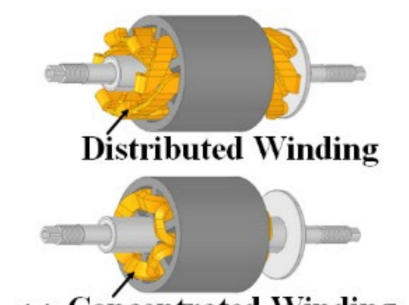

(a) Concentrated Winding
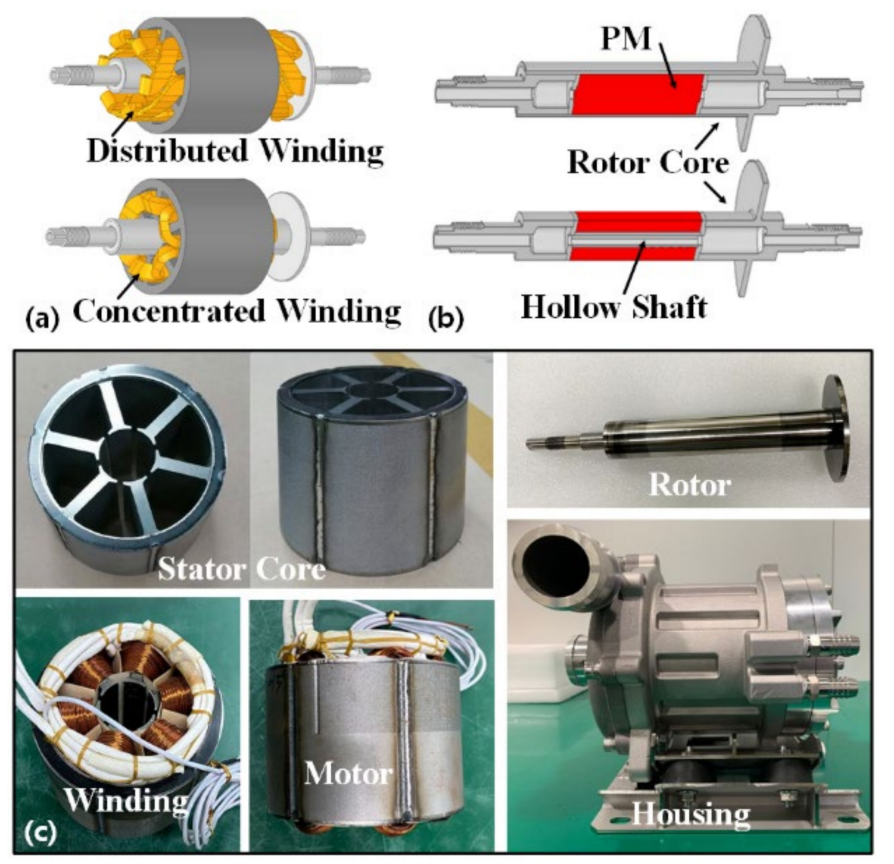

Figure 1. 3D structure of (a) two different winding patterns, (b) two different rotors, and (c) Manufactured model of concentrated winding motor.

\section{Electromagnetic Effects of Winding Patterns}

In this section a more efficient winding method through analytical approach for electromagnetic characteristics according to the winding method is presented. Generally, the power density per volume of the stator and rotor is higher in the case of a distributed winding than that of a concentrated winding motor. Therefore, it can be viewed efficiently. However, compared to the concentrated winding motor, there is a difficulty in manufacturing according to the distributed winding method, and the length of the end turn increases as the slot interval increases, and the size of the motor may increase. Therefore, the appropriate winding method should be selected in consideration of design conditions. In this study, the concentrated and distributed winding models were designed according to the given motor design specifications, and comparative analysis was performed considering the electromagnetic and mechanical properties.

\subsection{Winding Pattern}

Figure 2 shows the stator layouts and flux line distribution according to the armature reactions of a 2 pole/ 6 slot combination high-speed motors under the same conditions. As a model with a two-pole rotor, it can be confirmed that the distribution is symmetrical. Moreover, in the case of the distributed winding, it can be seen that the flow of magnetic flux distribution is wider than that of the concentrated winding. Therefore, with the flow of a wider magnetic flux in the distributed winding, it has a similar back EMF, despite fewer winding turns. This means that the distributed winding of this model has a higher magnetic flux density on the rotor than the concentrated winding. Accordingly, the results of the winding design using FEM are shown in Table 1. In the case of the distributed winding, the number of turns per slot was reduced by 12 turns compared to the concentrated winding. As a result, the winding resistance was significantly reduced from $0.04 \mathrm{ohms}$ to $0.01 \mathrm{ohms}$, and the inductance was also reduced. 


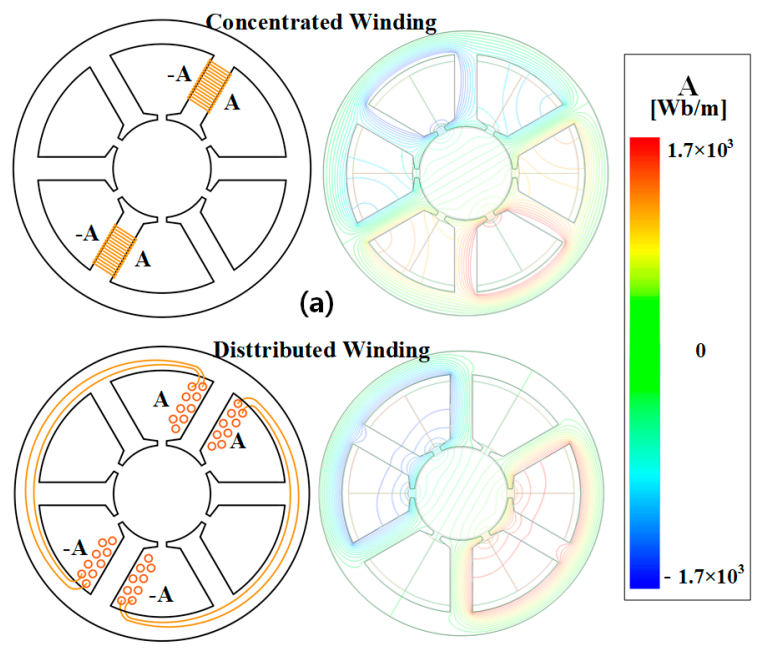

Figure 2. Stator layouts and magnetic flux line distribution according to armature reaction of a 2 pole 6 slot motor (a) concentrated, (b) distribute winding model.

Table 1. High speed motor design specifications according to winding patterns.

\begin{tabular}{cccc}
\hline Characteristic & Concentrated Winding & Distributed Winding & Unit \\
\hline Stack length & \multicolumn{2}{c}{90} & $\mathrm{~mm}$ \\
\hline Outer diameter of stator/rotor & \multicolumn{2}{c}{$96 / 30$} & $\mathrm{~mm}$ \\
\hline Turns & 15 & 9 & - \\
\hline Resistance & 0.04 & 0.01 & $\Omega$ \\
\hline Synchronous Inductance & 0.4 & 0.22 & $\mathrm{mH}$ \\
\hline Induced Voltage & 175 & 177 & $\mathrm{~V}_{\mathrm{rms}}$ \\
\hline
\end{tabular}

\subsection{Unbalanced Magnetic Force Analysis}

Depending on the winding combination, it may cause asymmetry or harmonic of the air gap magnetic flux density. This causes an unbalanced magnetic force, and this unbalanced electromagnetic force is a major cause of vibration and noise along with the static and dynamic eccentricity of the rotor. Therefore, to design a high-speed motor with improved performance, the unbalanced electromagnetic force of the winding combination of concentrated and distributed windings was derived and analyzed.

The electromagnetic force generated in the motor's air gap can be derived through the Maxwell stress tensor, and if this is expressed mathematically in a two-dimensional analysis, it is as follows in Equation (1):

$$
F=\frac{1}{\mu_{0}}\left(B_{n}^{2}-\frac{1}{2}|B|^{2}\right) i_{n}-\frac{1}{\mu_{0}} B_{n} B_{t} i_{t}
$$

Here, $\mu_{0}$ is the permeability of the vacuum. $B$ is the magnetic flux density. $B_{n}$ and $B_{t}$ are vertical and horizontal magnetic flux densities, respectively. $i_{n}$ and $i_{t}$ represent vertical and horizontal directions, respectively. It can be calculated from Maxwell's stress method through the force density distribution Equations (2) and (3) in the radial and circumferential directions,

$$
\begin{gathered}
f_{r}=\frac{1}{2 \mu_{0}}\left(B_{r g}^{2}-B_{\theta g}^{2}\right) \\
f_{\theta}=\frac{1}{\mu_{0}}\left(B_{r g} B_{\theta g}\right)
\end{gathered}
$$


Here, $B_{r g}$ and $B_{\theta g}$ are the magnetic flux densities in the radial and circumferential directions at the air-gap center, respectively, and $l_{s t k}$ is axial length of the stator core.

After converting these to a rectangular coordinate system, it is possible to obtain the direction and magnitude of the force received when the rotor rotates by integrating the area, whereas the force density distribution in the radial and circumferential directions exist. This is the same as in Equations (4) and (5) below:

$$
\begin{gathered}
F_{x}=\left[\frac{r l_{s t k}}{2 \mu_{0}}\right] \int_{0}^{2 \pi}\left[\left(B_{\theta g}^{2}-B_{r g}^{2}\right) \cos \theta+2 B_{r g} B_{\theta g} \sin \theta\right] d \theta \\
F_{y}=\frac{r l_{s t k}}{2 \mu_{o}} \int_{0}^{2 \pi}\left[\left(B_{\theta g}^{2}-B_{r g}^{2}\right) \sin \theta+2 B_{r g} B_{\theta g} \cos \theta\right] d \theta
\end{gathered}
$$

Through these equations, an analysis of the unbalanced magnetic force (UMF) characteristics of the PM motor and the distribution characteristics of the force density was performed and compared.

Figure $3 \mathrm{a}, \mathrm{b}$ shows the magnetic pull force (MPF) analysis results according to the winding method at a rated load, and Figure $3 c$,d shows the results of UMF analysis according to the winding method at a rated load. Both models have different waveforms, but they are symmetrically distributed. This means that the vibration caused by an unbalanced magnetic force in both models is small.

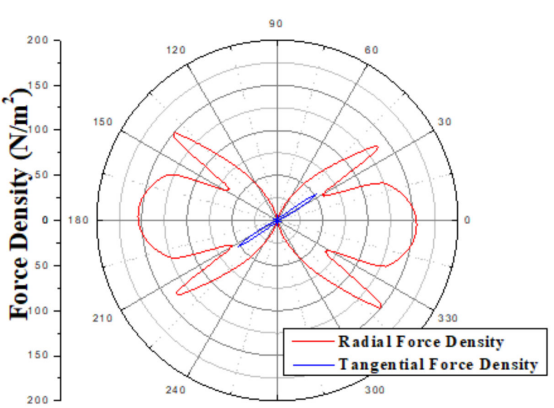

(a)

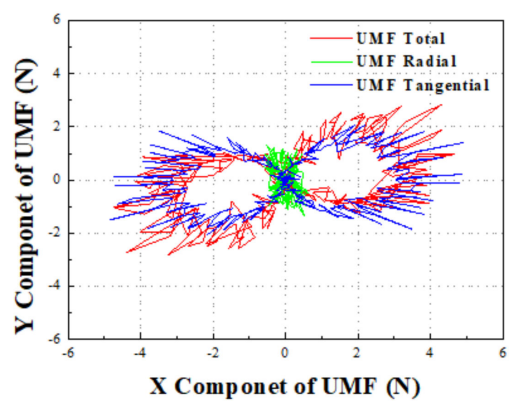

(c)

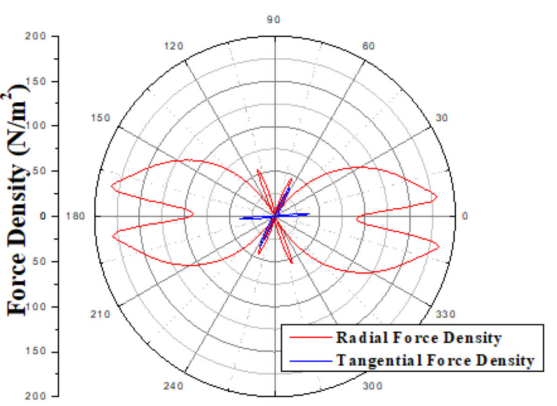

(b)

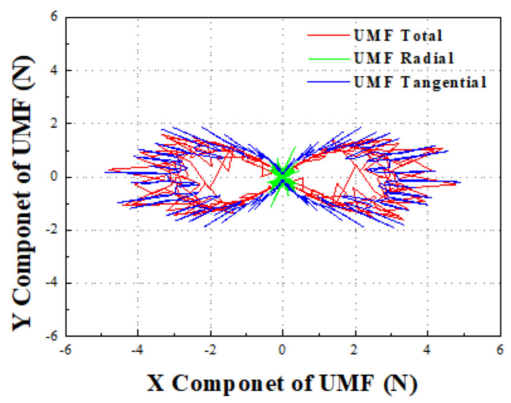

(d)

Figure 3. MPF analysis results according to (a) concentrated winding and (b) distributed winding and UMF analysis results according to (c) concentrated winding and (d) distributed winding.

\subsection{Magneto-Motive Force Analysis}

In this chapter, space harmonic magneto-motive force (MMF), one of the main causes of rotor eddy current loss in high-speed PM motors, was comparatively analyzed through analytical methods. The MMF owing to the winding structure and distribution was compared and analyzed using the space harmonic method. The space harmonics method is an electromagnetic field analysis technique that obtains the magnetic vector potential from the Maxwell Equation. Using this analysis method, MMF analysis of a high-speed motor was performed [8]. Based on the Maxwell Equation, the magnetic flux density $\mathbf{B}$, the magnetic field strength $\mathbf{H}$, and the magnetization strength $\mathbf{M}$ are based on the relationship 
of Equation (6). The magnetic vector potential A has a distribution characteristic according to the number of pole pairs $p$ and the space harmonic coefficient $n$ in the $\theta$ direction, and the magnitude has a rate of change in the $r$ direction. This is summarized as an equation with periodicity, as shown in the following Equation (7),

$$
\begin{gathered}
\nabla \times \mathbf{B}=\nabla \times(\nabla \times \mathbf{A})=\mu_{0} \nabla \times(\mathbf{M}+\mathbf{H}) \\
\mathbf{A}=A_{z n}(r) e^{-j n p \theta} i_{z}
\end{gathered}
$$

Then, the magnetic vector potential Equation (7) and the current modeling of the pole slot are calculated, and the following Equation (8) is derived, where $\mathbf{J}$ denotes the current density. In Equation (8), the following magnetic vector potential Equation (9) was derived by solving the characteristic equations using the condition of $\mathbf{J}=0$, when $r$ is the air-gap center. By applying it to the magnetic vector potential definition, the magnetic flux density equation was derived as shown in Equations (10) and (11):

$$
\begin{gathered}
\nabla^{2} A=-\mu_{0} J=\left(\frac{\partial^{2}}{\partial r^{2}} A(r)+\frac{1}{r} \frac{\partial}{\partial r} A(r)-\frac{(n p)^{2}}{r^{2}} A(r)\right) e^{-j n p \theta} \\
A(r)=\sum_{n=o d d}^{\infty}\left\{C_{n}^{1} r^{n p}+D_{n}^{1} r^{-n p}\right\} e^{-j n p \theta} \\
B_{r}(r)=\sum_{n=-\infty}^{\infty}\left\{\frac{-j n p}{r}\left(C_{n} r^{n p}+D_{n} r^{-n p}\right) e^{-j n p \theta}\right\} \\
B_{\theta}(r)=\sum_{n=-\infty}^{\infty}\left\{\frac{-n p}{r}\left(C_{n} r^{n p}-D_{n} r^{-n p}\right) e^{-j n p \theta}\right\}
\end{gathered}
$$

Finally, the magnetic flux density Equations (10) and (11) were applied to the boundary conditions according to the permeability to derive the final air-gap magnetic flux density graph [9]. Equation (12) below shows the relationship between the magnetic flux density and the magnetic force distribution,

$$
B=\frac{1}{S} \frac{\mu_{o} S}{l_{g}} f_{m}=\frac{\mu_{o}}{l_{g}} f_{m}=P_{r} f_{m}
$$

Here, $S$ is the area of over which magnetic flux passes. $f_{m}$ is the MMF, and $l_{g}$ is the length of the air-gap.

At this time, in the case of a rotary machine with a uniform air-gap, the air-gap magnetic flux density distribution is the same as the magnetic force distribution and the waveform according to a certain specific permeability $\left(P_{r}\right)$ [10]. Therefore, based on the derived air-gap magnetic flux density, the final MMF distribution as shown in Figure 4 was derived. At this time, the phase currents of the two winding methods have the same rms value, and both were analyzed based on $1 \mathrm{~A}$.

As a result, it was confirmed that the MMF waveforms derived through the air-gap magnetic flux density were generally consistent with the ideal MMF waveform considering only the winding pattern. This suggests the validity of Equation (12) applied in this study, and harmonic components were compared for a more detailed analysis. Figure 5 shows the harmonic components of MMF according to the analytical method and FEM used in this study. Although there is a difference in the harmonic magnitude, it can be confirmed that the distribution for the harmonic order is generally the same. In addition, it was confirmed that the MMF of the distributed winding model was slightly large. Therefore, as shown in Table 2, it is considered that the distributed winding model has a similar eddy current loss despite the smaller input current. 


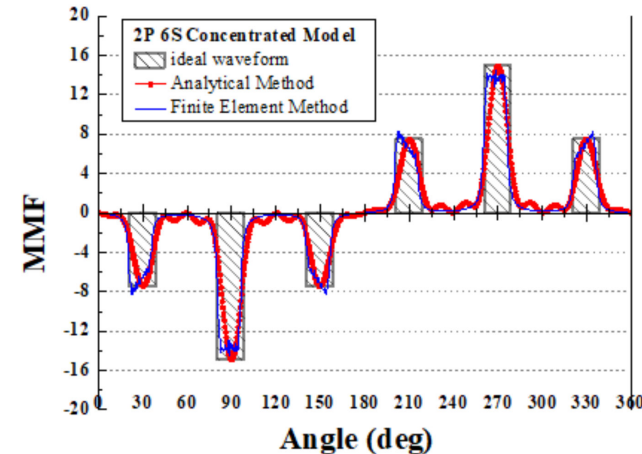

(a)

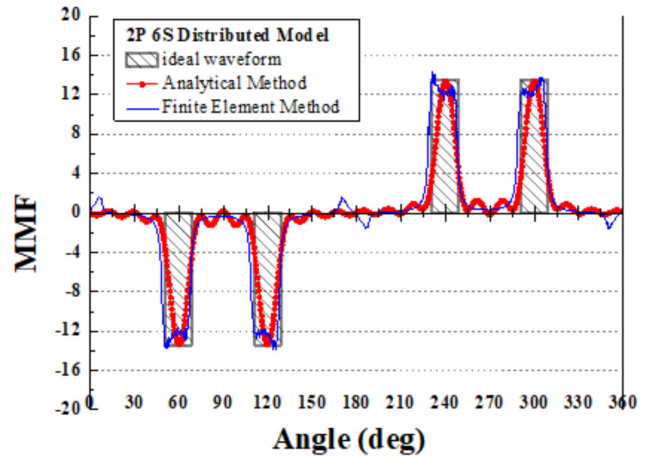

(b)

Figure 4. Comparison of MMF waveforms according to analysis methods of (a) concentrated model and (b) distributed model.

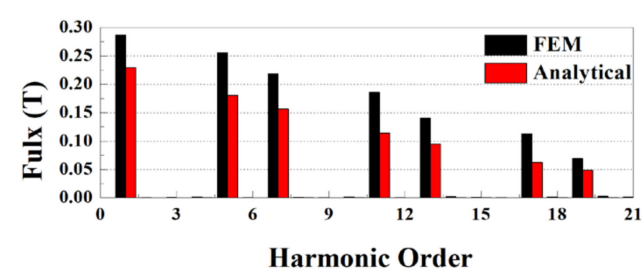

(a)

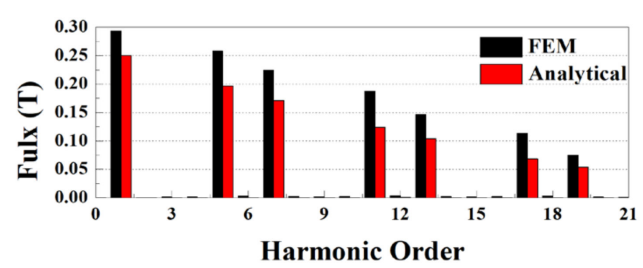

(b)

Figure 5. MMF harmonic components of (a) concentrated model and (b) distributed model.

Table 2. High speed motor design specifications according to winding patterns.

\begin{tabular}{cccc}
\hline Characteristic & Concentrated Winding & Distributed Winding & Unit \\
\hline Input Current & 23.5 & 22.6 & $\mathrm{~A}_{\text {rms }}$ \\
Torque & 1.41 & 1.41 & $\mathrm{~N} . \mathrm{m}$ \\
Output Power & 12.1 & 12.1 & $\mathrm{~kW}$ \\
Core Loss & 392.46 & 390.75 & $\mathrm{~W}$ \\
Eddy current Loss & 210.06 & 208.82 & $\mathrm{~W}$ \\
Copper Loss & 66.27 & 15.32 & $\mathrm{~W}$ \\
Efficiency & 94.7 & 95.1 & $\%$ \\
\hline
\end{tabular}

\section{Current Harmonics according to Winding Patterns}

The PM motor is driven by an inverter, and the generated PWM signal induces highfrequency components that affect the electromagnetic loss at each carrier frequency. In this section, the harmonic current according to the winding method was derived as a method in which the current through the current loop tracks the commanded current. After that, based on the result of comparison of electromagnetic properties, the final winding method is presented.

\subsection{Dynamic Simulation}

Figure 6 shows the PMSM dynamic simulation block diagram applied in this study. The overall system includes two closed loops: an inner current control loop, and an outer speed control loop. The current loop tracks the actual current to obtain the desired current. Figure 7a shows the estimated harmonic current through simulation according to winding patterns. Figure $7 \mathrm{~b}$ shows the result of harmonic analysis of the estimated currents. In general, when the inductance is very small in a high-speed motor, the harmonics due to PWM are greatly affected [11]. As can be seen in Table 1, the inductance in the distributed winding smaller than in the concentrated winding, so the current harmonic component was generated larger in the distributed winding model according to Figure $7 \mathrm{~b}$. 


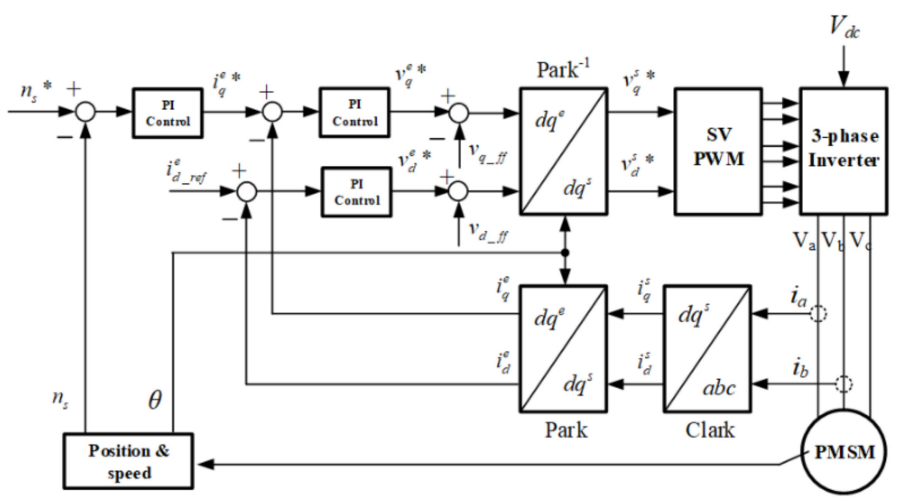

Figure 6. Dynamic simulation block diagram.

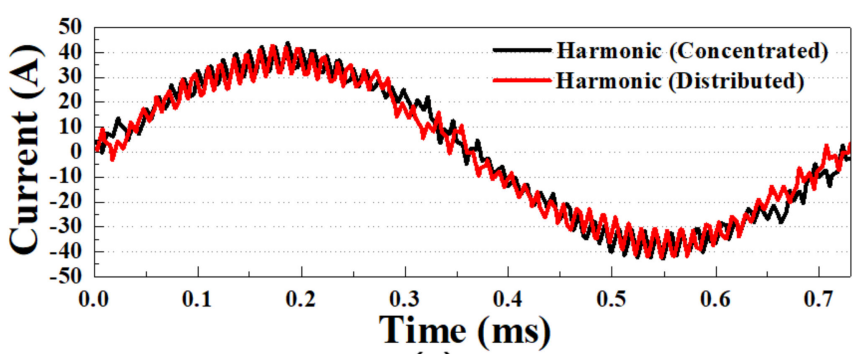

(a)

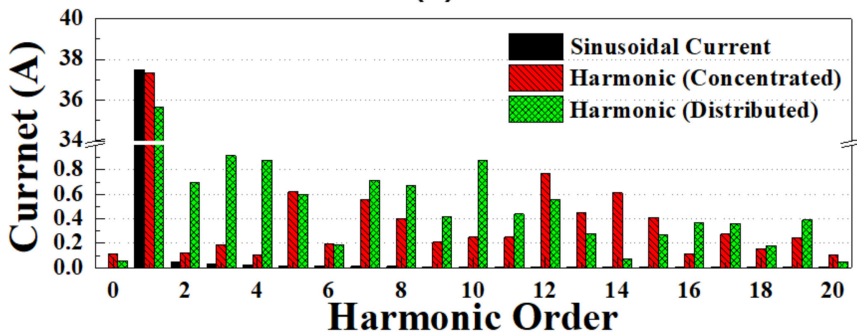

(b)

Figure 7. (a) Phase current waveforms and (b) harmonic components according to currents.

\subsection{Electromagnetic Loss}

Table 3 shows the electromagnetic loss analysis results owing to current harmonics. Both winding methods have higher losses than conventional methods (sinusoidal current) when considering the current harmonics. Figure 8 shows the loss distribution according to the current waveforms. Among them, the distributed winding model showed the largest increase of $34 \%$ in the core loss case, and 35\% for the eddy current loss. Accordingly, the more detailed analysis of the electromagnetic losses generated owing to the current harmonics was performed. The Steinmetz Equation for calculating the core loss is as the following Equation (13).

$$
P_{\text {core }}=P_{h}+P_{e}+P_{a}=k_{h} f_{c} B^{n_{s t}}+k_{e} f_{c}^{2} B^{2}+k_{a} f_{c}^{1.5} B_{c}{ }^{1.5}
$$

Table 3. Comparison of electromagnetic losses obtained using FEM analysis.

\begin{tabular}{ccccc}
\hline Loss & Current & Concentrated Winding & Distributed Winding & Unit \\
\hline \multirow{2}{*}{ Core Loss } & Sinusoidal & 392.46 & 390.75 & $\mathrm{~W}$ \\
Eddy Current & Harmonics & 514.5 & 524.4 & $\mathrm{~W}$ \\
Loss & Sinusoidal & 210.06 & 208.82 & $\mathrm{~W}$ \\
& Harmonics & 275 & 282.2 & $\mathrm{~W}$ \\
\hline
\end{tabular}




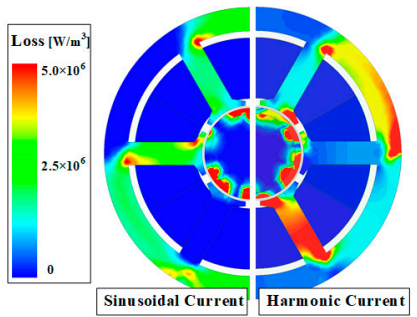

(a)

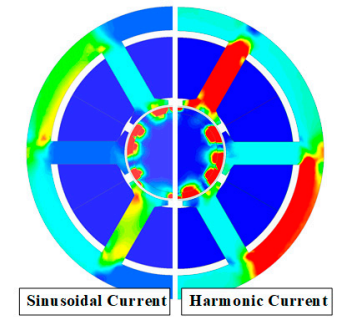

(b)

Figure 8. Electromagnetic loss distribution according to current waveform of (a) the concentrated and $(\mathbf{b})$ distributed winding models.

Here, $P_{h}, P_{e}$, and $P_{a}$ are the hysteresis loss, eddy current loss, and the anomalous loss in the iron core, respectively; and $k_{h}, k_{e}$, and $k_{a}$ are the core loss coefficients from the core loss data for steel to calculate the core loss in a stator core, of the frequency functions. $n_{s t}$ is the Steinmetz constant. $f_{c}$ and $B$ are the frequency of the external magnetic field and flux density in the core, respectively, and the eddy current loss was expressed as in Equation (14) [12].

$$
W_{\text {mag }}=\sum_{n} \int \frac{J_{n}}{2 \sigma} d v
$$

Here, $W_{m a g}$ is the eddy current loss, $J_{n}$ is the time harmonic current density of the nth harmonic, and $\sigma$ is the conductivity. The loss Equations (12) and (13) prove that the current harmonics can cause additional electromagnetic losses when the harmonic order $n$ increases as a result of comparing the electromagnetic characteristics considering the space harmonics of MMF and time harmonics of current according to the winding patterns, which confirmed that the concentrated winding method is more efficient in this model.

\section{Effects of Shaft Shapes}

In this section, a hollow rotor shaft is applied to reduce the amount of magnets used in conventional high-speed motors. Therefore, the influence of the electromagnetic and mechanical properties of the application of the hollow shaft on the winding methods was comparatively analyzed through analysis. The inner magnet radius was based on $5(\mathrm{~mm})$, which is the motor shaft size. In addition, the resulting difference in weight of the rotor can be seen from Table 4.

Table 4. Rotor weight according to shaft shape.

\begin{tabular}{cccccc}
\hline Type & Sleeve & PM & Shaft & Total & Unit \\
\hline Solid Shaft & 0.13 & 0.37 & - & 0.5 & $\mathrm{Kg}$ \\
Hollow Shaft & 0.13 & 0.31 & 0.03 & 0.48 & $\mathrm{Kg}$ \\
\hline
\end{tabular}

\subsection{Electromagnetic Characteristics}

Table 5 shows the result of the concentrated winding model according to rotor shape. The output reduction owing to the decreased magnet usage was compensated for by an increase of about $1 \mathrm{~A}_{\mathrm{rms}}$ of the applied power. Accordingly, it was confirmed that the copper loss increased by approximately $10 \mathrm{~W}$, but there was no significant difference in terms of efficiency. In addition, the magnet reduction owing to the hollow shaft application reduced the stator core loss, but the eddy current loss increased owing to the current increase. Similarly, the total loss was no significant difference. This suggests that the presence or absence of a rotor hollow shaft does not significantly affect the electromagnetic efficiency. 
Table 5. High speed motor design specifications according to shaft shape.

\begin{tabular}{cccc}
\hline Characteristic & Solid Shaft & Hollow Shaft & Unit \\
\hline Input Current & 24.1 & 25.2 & $\mathrm{~A}_{\text {rms }}$ \\
Torque & 1.41 & 1.41 & $\mathrm{~N} . \mathrm{m}$ \\
Output Power & 12.16 & 12.15 & $\mathrm{~kW}$ \\
Core Loss & 515.4 & 487.4 & $\mathrm{~W}$ \\
Eddy current Loss & 275 & 289.7 & $\mathrm{~W}$ \\
Copper Loss & 69.6 & 75.6 & $\mathrm{~W}$ \\
Efficiency & 93.4 & 93.4 & $\%$ \\
\hline
\end{tabular}

\subsection{Mechanical Characteristics}

The natural frequency of the rotor is the main frequency at which the stator's vibration and noise occur. Therefore, when designing a high-speed motor, it is essential to analyze mechanical characteristics. In this chapter, the analysis of mechanical characteristics according to the shape of the rotor and the winding patterns was performed using an FEM.

Figure 9 shows the natural frequency derived according to the driving speed based on the analysis result as a Campbell diagram. It was confirmed that the solid shaft model had a critical speed of 53,800 rpm, and the hollow shaft model had a critical speed of $26,500 \mathrm{rpm}$. Additionally, Figure 10 is the result of analyzing the stress that current exerts on the hollow shaft rotor for each frequency. Even in the hollow shaft model, it can be seen that the concentrated winding with less stress is more effective. Therefore, even if the hollow shaft was applied, there was no significant electromagnetic difference and it was confirmed that there was no driving problem, even if the mechanical characteristics were considered.

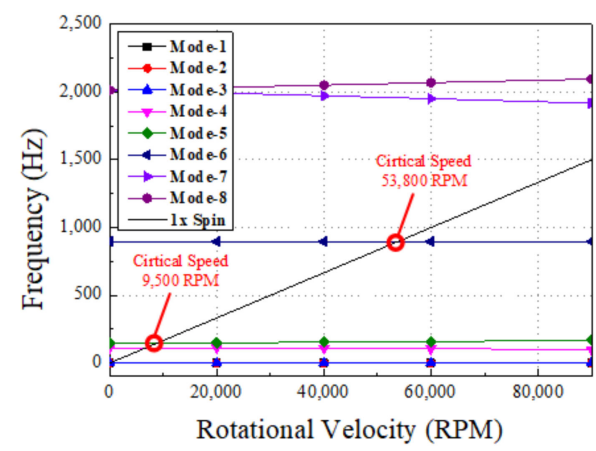

(a)

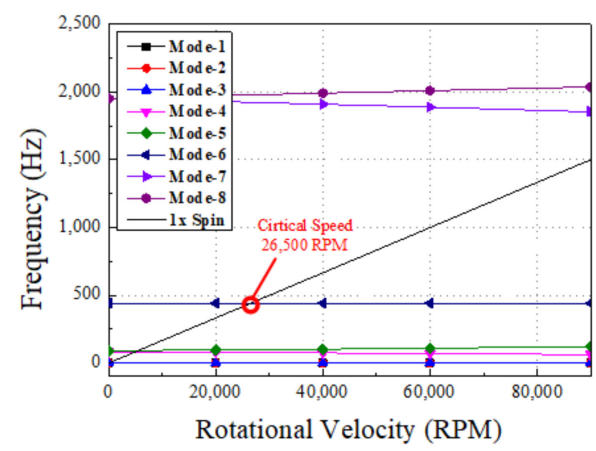

(b)

Figure 9. Critical speed analysis results of two different rotors (a) solid shaft, (b) hollow shaft.

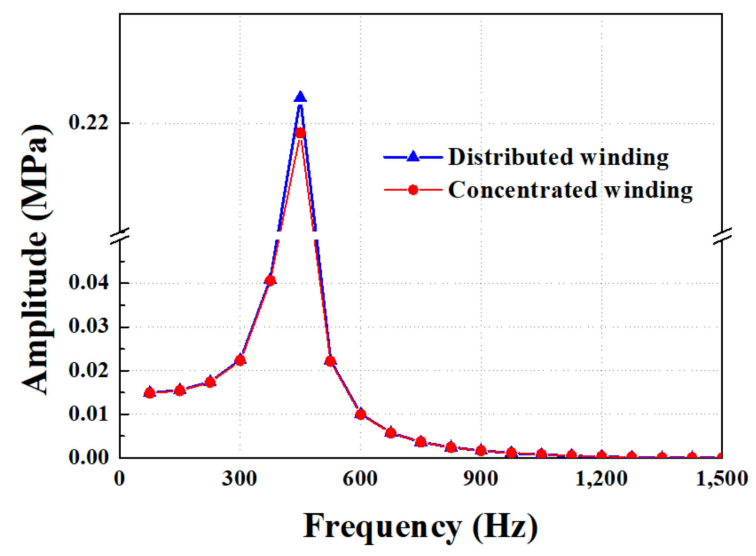

Figure 10. Stress applied to the hollow shaft rotor according to the winding method for each frequency. 


\section{Experiment Analysis}

In the previous section, the final model was presented based on the analysis results according to the winding method and rotor shape. Therefore, the concentrated winding model with a hollow shaft rotor was selected as the final model, and an experiment was performed using a manufactured model. However, the requirement of speed and torque is higher than for conventional electrical machines; thus, it cannot be directly measured with a dynamometer. Therefore, it is necessary that an air-compressor system is constructed by using mechanical components for evaluation performance of machines. In the case of speed, it was derived through the frequency of the current, and in the case of torque, an impeller was attached to the opposite side and calculated inversely by using mechanical equations. However, impeller shape and efficiency equations for overall systems keep the manufacturer confidential, so we have not written them in this paper.

Figure 11 shows the back electromotive force (EMF) between lines in the no-load experiment. When considering the 3D structure and the hollow shaft in consideration of the magnet leakage, it can be confirmed that it is most similar to the no-load back EMF of the actual manufactured model. Table 6 shows the load test results. This is a comparison of the experimental results with the application of the harmonic current derived in this study. The applied current and the counter electromotive forces are similar, but in the case of the output, it is slightly reduced.

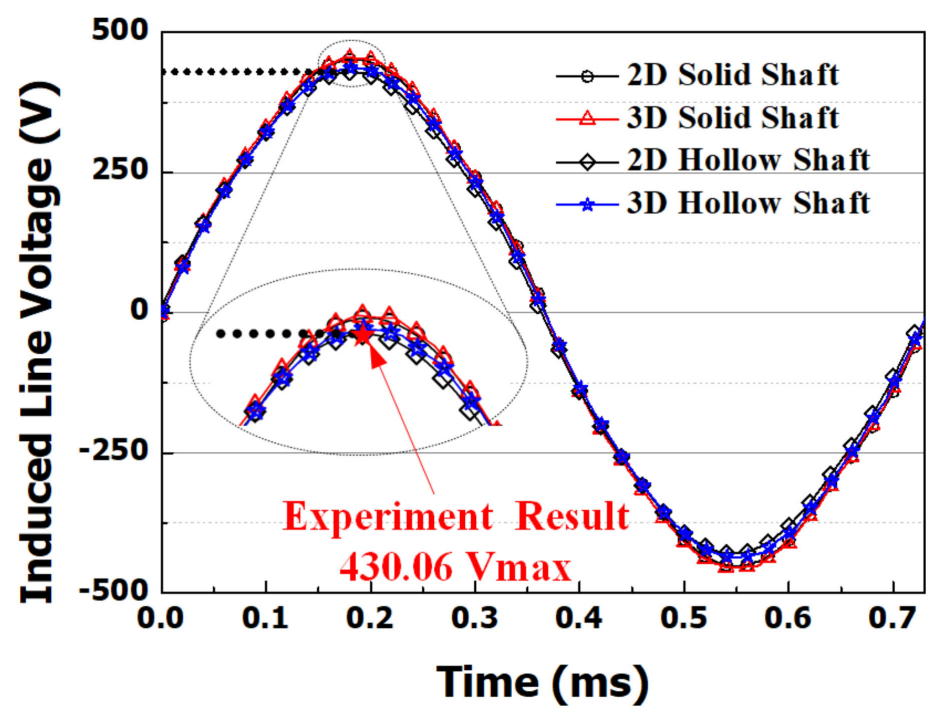

Figure 11. Line voltage at no-load condition.

Table 6. Comparison of electromagnetic characteristics obtained using FEM analysis and experiment.

\begin{tabular}{ccccc}
\hline Characteristic & $\begin{array}{c}\text { Back EMF } \\
\text { (Vrms) }\end{array}$ & $\begin{array}{c}\text { Current } \\
\text { (Arms) }\end{array}$ & $\begin{array}{c}\text { Torque } \\
\text { (N.m) }\end{array}$ & $\begin{array}{c}\text { Output Power } \\
\text { (kW) }\end{array}$ \\
\hline FEM & 175.3 & 25.2 & 1.43 & 12.3 \\
Experiment & 175.5 & 25.5 & 1.41 & 12.1 \\
\hline
\end{tabular}

Figure 12 shows the corresponding results of the power characteristics according to the speed. The loss determined considering the applied power was defined as the motor system loss, and the electromagnetic loss considering the current harmonics was compared with that obtained experimentally. 


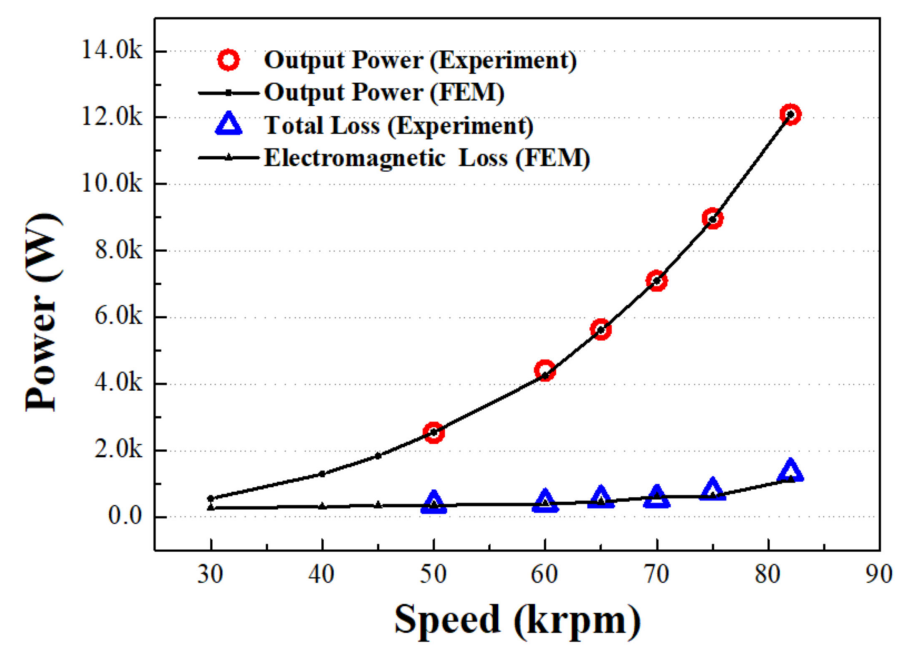

Figure 12. Load experiment results for concentrated model.

The results of the experiment indicate that the motor exhibit a similar output power of the analysis results with efficiencies of $92 \%$ at the rated speed. However, it can be seen that the loss of most experimental results is slightly higher. In the actual experimental case, it is believed that the difference occurred owing to the addition of friction loss. This approach can thus be considered as a reasonably accurate electromagnetic loss analysis method in the design process before the motor is manufactured.

\section{Conclusions}

This study deals with the electromagnetic characteristics analysis according to the winding patterns of a high-speed PM motor. Analysis was performed with the goal of reducing eddy current loss to improve the efficiency of high-speed PM motors. Accordingly, the major causes of eddy current loss were selected as space harmonics of MMF and time harmonics of current, and the electromagnetic effects of winding distribution closely related to the two causes were compared and analyzed by using analytical methods and FEM.

In general, it is known that the distributed winding waveform has fewer harmonics than the concentrated winding waveform, and so it is excellent. However, in this study, it was confirmed that the increased electromagnetic loss of the distributed winding was higher when the MMF harmonics and the inverter were considered. Therefore, in this study's model, it was suggested that the distributed winding was not unconditionally excellent, and the concentrated winding had a better performance as the final model. Subsequently, as a result of analyzing the electromagnetic and mechanical properties according to the rotor shape, it was confirmed that both methods slightly increased the applied current, but did not make a significant difference, and there was no driving problem. Accordingly, it was possible to design a high-speed motor with similar performance while reducing the amount of magnets used, and the validity was presented through experiments. It is considered that this can be used as a reference for designing high-speed PM motors and optimizing motor performance in the future.

Author Contributions: J.-Y.C.; conceptualization, review and editing, J.-H.W.; original draft preparation, formal analysis and validation, J.-I.L.; methodology and writing, T.-K.B.; writing and formal analysis, H.-K.L.; validation and software. All authors have read and agreed to the published version of the manuscript.

Funding: This research was supported by the Basic Science Research Program through the National Research Foundation of Korea (NRF-2020R1A4A2002021) and this work was supported by the National Research Foundation of Korea (NRF) grant funded by the Korea government (MSIT). (No. 2020R1A2C1007353).

Institutional Review Board Statement: Not applicable. 
Informed Consent Statement: Not applicable.

Conflicts of Interest: The authors declare no conflict of interest.

\section{References}

1. Qiu, H.; Tang, B.; Yu, W.; Yuan, S.; Wu, J.; Yang, C.; Cui, G. Analysis of the super high-speed permanent magnet generator under unbalanced load condition. IET Electr. Power Appl. 2017, 11, 1492-1498. [CrossRef]

2. Zhang, Y.; McLoone, S.; Cao, W.; Qiu, F.; Gerada, C. Power Loss and Thermal Analysis of a MW High-Speed Permanent Magnet Synchronous Machine. IEEE Trans. Energy Convers. 2017, 32, 1468-1478. [CrossRef]

3. Niu, S.; Ho, S.L.; Fu, W.N.; Zhu, J. Eddy Current Reduction in High-Speed Machines and Eddy Current Loss Analysis with Multislice Time-Stepping Finite-Element Method. IEEE Trans. Magn. 2012, 48, 1007-1010. [CrossRef]

4. Ishak, D.; Zhu, Z.; Howe, D. Eddy-current loss in the rotor magnets of permanent-magnet brushless machines having a fractional number of slots per pole. IEEE Trans. Magn. 2005, 41, 2462-2469. [CrossRef]

5. Phyu, H.N.; Aung, N.L.; Bi, C. Influence of Winding Structure and the Effect of MMF Harmonics to the Spindle Motor Performance for Ultrahigh TPI HDD. IEEE Trans. Magn. 2013, 49, 2776-2781. [CrossRef]

6. Ponomarev, P.; Lindh, P.; Pyrhönen, J.J. Effect of Slot-and-Pole Combination on the Leakage Inductance and the Performance of Tooth-Coil Permanent-Magnet Synchronous Machines. IEEE Trans. Ind. Electron. 2013, 60, 4310-4317. [CrossRef]

7. Huang, Z.; Fang, J. Multiphysics Design and Optimization of High-Speed Permanent-Magnet Electrical Machines for Air Blower Applications. IEEE Trans. Ind. Electron. 2016, 63, 2766-2774. [CrossRef]

8. Virtic, P.; Pisek, P.; Hadziselimovic, M.; Marcic, T.; Stumberger, B. Torque Analysis of an Axial Flux Permanent Magnet Synchronous Machine by Using Analytical Magnetic Field Calculation. IEEE Trans. Magn. 2009, 45, 1036-1039. [CrossRef]

9. Choi, J.-Y.; Lee, S.-H.; Ko, K.-J.; Jang, S.-M. Improved Analytical Model for Electromagnetic Analysis of Axial Flux Machines With Double-Sided Permanent Magnet Rotor and Coreless Stator Windings. IEEE Trans. Magn. 2011, 47, 2760-2763. [CrossRef]

10. Kang, H.; Zhou, L.; Wang, J. Harmonic winding factors and MMF analysis for five-phase fractional-slot concentrated winding PMSM. In Proceedings of the 2013 International Conference on Electrical Machines and Systems (ICEMS), Busan, Korea, 26-29 October 2013; pp. 1236-1241.

11. Liangliang, C.; Lan, X.; Wenbin, H.; Yangguang, Y. Application of coupled inductors in parallel inverter system. In Proceedings of the Sixth International Conference on Electrical Machines and Systems, Beijing, China, 9-11 November 2003; pp. 398-401.

12. Jeong, T.-C.; Lee, K.-D.; Han, J.-H.; Sung, T.-H.; Kim, W.-H.; Kim, M.-J.; Lee, J.-J.; Kim, H.-J.; Lee, J. Current Harmonics Loss Analysis of 150-kW Traction Interior Permanent Magnet Synchronous Motor Through Co-Analysis of d-q Axis Current Control and Finite Element Method. IEEE Trans. Magn. 2013, 49, 2343-2346. [CrossRef] 